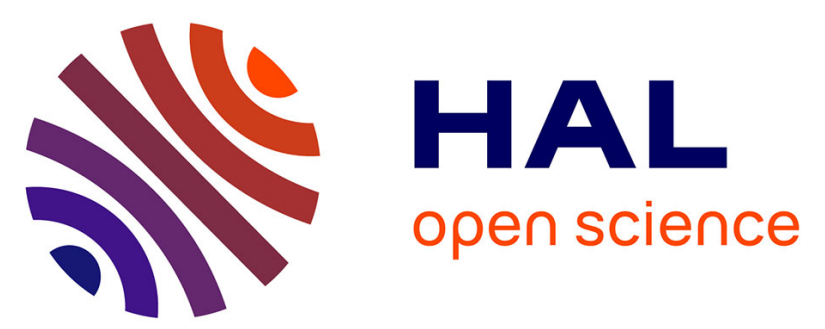

\title{
Assessing the protective effect of vertically heterogeneous canopies against radiative frost: The case of quinoa on the Andean Altiplano
}

T. Winkel, J.P. Lhomme, J.P. Nina Nina Laura, C Mamani Alcón, C. del Castillo, A. Rocheteau

\section{To cite this version:}

T. Winkel, J.P. Lhomme, J.P. Nina Nina Laura, C Mamani Alcón, C. del Castillo, et al.. Assessing the protective effect of vertically heterogeneous canopies against radiative frost: The case of quinoa on the Andean Altiplano. Agricultural and Forest Meteorology, 2009, 149 (10), pp.1759 - 1768. 10.1016/j.agrformet.2009.06.005 . ird-03373194

\section{HAL Id: ird-03373194 \\ https://hal.ird.fr/ird-03373194}

Submitted on 11 Oct 2021

HAL is a multi-disciplinary open access archive for the deposit and dissemination of scientific research documents, whether they are published or not. The documents may come from teaching and research institutions in France or abroad, or from public or private research centers.
L'archive ouverte pluridisciplinaire HAL, est destinée au dépôt et à la diffusion de documents scientifiques de niveau recherche, publiés ou non, émanant des établissements d'enseignement et de recherche français ou étrangers, des laboratoires publics ou privés. 
Provided for non-commercial research and education use. Not for reproduction, distribution or commercial use.

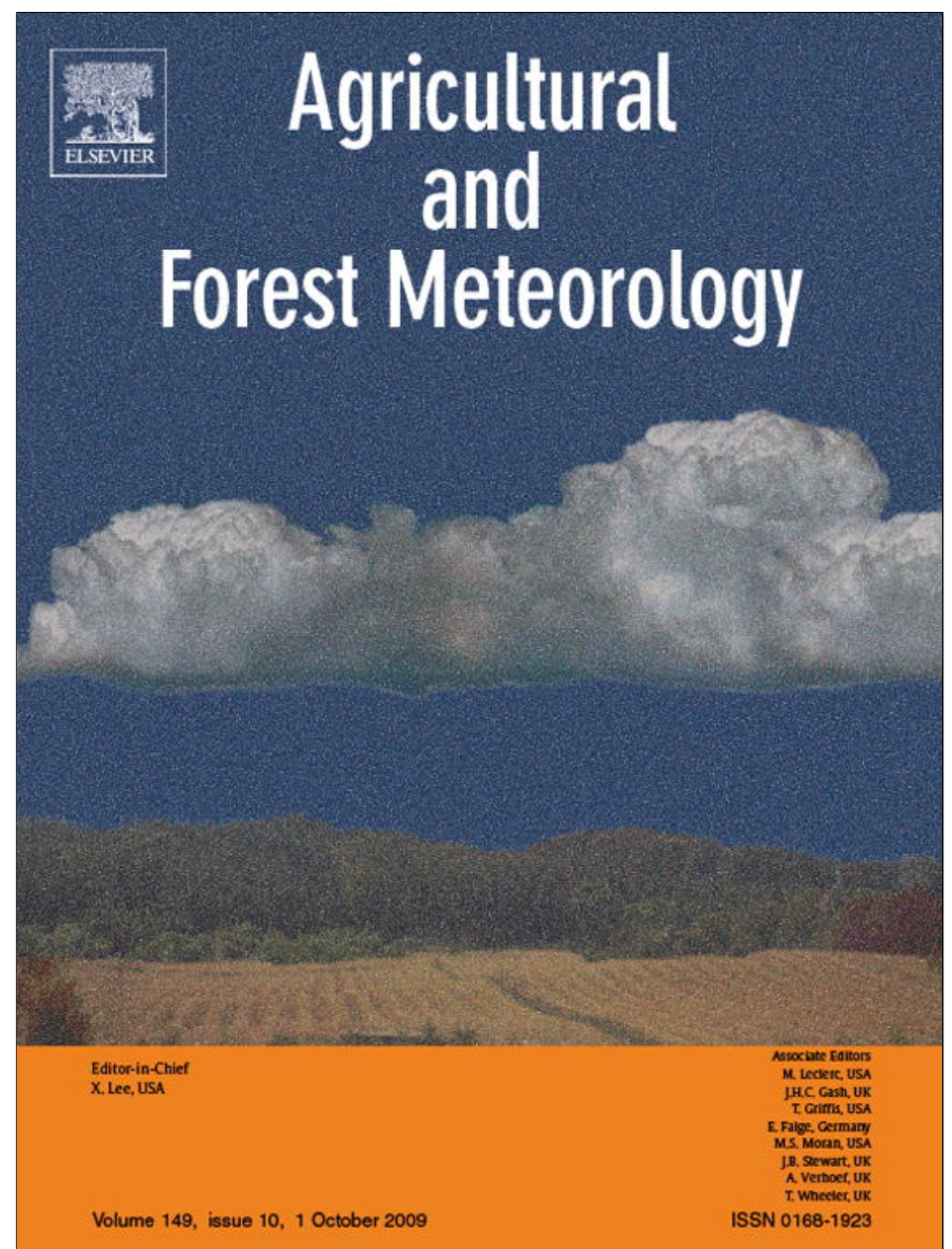

This article appeared in a journal published by Elsevier. The attached copy is furnished to the author for internal non-commercial research and education use, including for instruction at the authors institution and sharing with colleagues.

Other uses, including reproduction and distribution, or selling or licensing copies, or posting to personal, institutional or third party websites are prohibited.

In most cases authors are permitted to post their version of the article (e.g. in Word or Tex form) to their personal website or institutional repository. Authors requiring further information regarding Elsevier's archiving and manuscript policies are encouraged to visit:

http://www.elsevier.com/copyright 


\title{
Assessing the protective effect of vertically heterogeneous canopies against radiative frost: The case of quinoa on the Andean Altiplano
}

\author{
T. Winkel ${ }^{\text {a,* }}$, J.P. Lhomme $^{\text {a }}$, J.P. Nina Laura ${ }^{\mathrm{b}}$, C. Mamani Alcón ${ }^{\mathrm{b}}$, C. del Castillo ${ }^{\mathrm{b}}$, A. Rocheteau ${ }^{\mathrm{a}}$ \\ a IRD, UR 060 “Climat et Fonctionnement des Agro-écosystèmes", CEFE-CNRS, F-34293 Montpellier Cedex 05, France \\ ${ }^{\mathrm{b}}$ Universidad Mayor de San Andrés, Facultad de Agronomía, La Paz, Bolivia
}

\section{A R T I C L E I N F O}

\section{Article history:}

Received 3 March 2009

Received in revised form 8 June 2009

Accepted 8 June 2009

\section{Keywords:}

Chenopodium quinoa

Canopy thermal stratification

Leaf temperature

Night conditions

Radiation view factor

\begin{abstract}
A B S T R A C T
Night radiative frost is a highly limiting factor for agriculture in Andean highlands. Nevertheless, a diversity of crop species have been domesticated there, commonly showing high heterogeneity in plant growth at the field level. The possible protective effect of crop canopy heterogeneity against nocturnal radiative frost is examined using a dual approach, combining a field experiment and a simplified energy balance model at the leaf level. Leaf and air temperatures were registered over an entire quinoa crop cycle in the Andean highlands of Bolivia, comparing two cultivars: Blanca de Yanamuyu, a traditional landrace with high plant height heterogeneity, and Surumi, a more homogeneous selected variety. In both cultivars, inverted air density profiles during calm and clear nights result in air temperature changes up to $3{ }^{\circ} \mathrm{C}$ over $0.5 \mathrm{~m}$ height, with minimum air temperature concentrated at the upper part of the canopy. In these conditions, leaf temperature gradients of up to $2.6{ }^{\circ} \mathrm{C} \mathrm{m}^{-1}$ develop within the canopy of the traditional landrace, with minimum leaf temperature significantly higher $(P<0.001)$ in shaded plants of the landrace than in the selected cultivar. A dynamic model of leaf temperature based on canopy parameters and climatic records at screen level adequately simulates leaf temperature differences in the case of a vertically heterogeneous quinoa canopy. A sensitivity analysis of the model reveals that canopy height, leaf area index, and sky cloudiness have the most important influences on the development of the sheltering effect, while air temperature and air humidity play a minor role under typical radiative frost conditions. As for wind speed, its actual influence remains unclear due to experimental and modelling limitations at low wind speeds. The significance of these results is discussed in terms of the trade-off between stress adaptation and biomass productivity.
\end{abstract}

(c) 2009 Elsevier B.V. All rights reserved.

\section{Introduction}

Night radiative frost is a major abiotic stress factor in high altitude tropics of the Andes (Rundel, 1994). Nocturnal radiative loss due to low air density at high elevation results in frequent night frost during the cool dry season, but also during the more temperate and humid cultivation period (Garcia et al., 2007; Geerts et al., 2006). These climatic risks have induced the farmers of the highlands of Bolivia, Ecuador and Peru to develop original agricultural techniques (Lhomme and Vacher, 2002; Morlon, 1996) and manipulate a diversity of crops species and landraces (Vacher, 1998) frequently showing great heterogeneity in plant growth and development within the same field.

The question then arises of the possible implication of plant height heterogeneity on the crop tolerance to night frost. While many experimental and modelling studies have considered canopy-atmosphere interactions in homogeneous crops and

\footnotetext{
* Corresponding author. Tel.: +33 4676132 74; fax: +33467412138.

E-mail address: thierry.winkel@ird.fr (T. Winkel).
}

grasslands, or in multi-layer tree canopies (Caramori et al., 1996; De Chantal et al., 2007; Groot and Carlson, 1996; Langvall and Ottonson Löfvenius, 2002; Leuning, 1988; Leuning and Cremer, 1988; Wang and Engel, 2002), few experimental data are available on leaf temperature variations within heterogeneous crop canopies under nocturnal cooling. Studies on highly diverse crops or intercropping systems have paid more attention to the role of plant or species diversity in the crop tolerance against environmental stresses such as drought, plagues or herbivory (e.g. Black and Ong, 2000; De Rouw and Winkel, 1998; Lambdon et al., 2003; Peleg et al., 2005), leading to theoretical developments about the portfolio effect or the insurance hypothesis (Lhomme and Winkel, 2002; Yachi and Loreau, 1999). These theoretical considerations generally predict that, in situations of environmental risks, plant heterogeneity enhances the stability in aggregate properties such as biomass production.

The effects of night frost on individual plants may be visible damage due to the freezing of aerial parts of the plants, or unperceived reduction in carbon assimilation due to photoinhibition persisting in the following days (Langvall and Orlander, 2001). Species-specific as well as ontogenetic variations in plant 
sensitivity to frost have been reported (e.g. Bois et al., 2006; Kalberer et al., 2006; Scowcroft et al., 2000; Taschler and Neuner, 2004). Part of these variations can be related to canopy architecture, as plant height and leaf density play a major role in controlling the energy exchanges between the canopy, the soil surface and the atmosphere (Feldhake, 2002; Porté et al., 2004). In multi-layer canopies, these architectural parameters determine the sky view factor, i.e. the fraction of sky exposure at any particular place within the canopy. Under clear and calm nights, the same factor directly controls the losses of radiant energy from the leaves to the cold night sky (Jordan and Smith, 1995a). Both empirical and theoretical studies suggest that small crops experience lower minimum temperatures than tall ones, while crops with high leaf area index (LAI) should be more prone to frost damage (Lhomme and Guilioni, 2004). Various plant morphological traits (plant growth habit, leaf shape, size, colour or hairiness, etc.) are also known to affect individual plant as well as whole canopy temperatures (Ayeneh et al., 2002; Jordan and Smith, 1995b; Leuning and Cremer, 1988).

The present study addressed the relations between plant height heterogeneity and crop tolerance to night radiative frost, starting from the hypothesis that heterogeneous crop canopies are more tolerant to frost because plants at different heights experience different degrees of nocturnal cooling. The quinoa crop (Chenopodium quinoa Willd.) provides a good experimental model to examine this question because of its remarkable frost tolerance (Jacobsen et al., 2007) and the high heterogeneity in plant height and branching (Bhargava et al., 2007b). This small grain species is native from the Andean highlands of Bolivia and Peru, where dozens of landraces were domesticated (Izquierdo Fernández et al., 2001; National Research Council, 1989). Though studies based on molecular markers do not yet indicate any trend of genetic erosion in the main regions of commercial production (Del Castillo et al., 2007), the quinoa crop has entered a process of standardization due to mechanized crop practices over extended monocultures in flat areas particularly prone to frost risk (François et al., 1999). In this context, the protective effect of canopy heterogeneity against nocturnal frost was investigated in quinoa using a dual approach based on (i) field experimentation in the Bolivian altiplano, and (ii) dynamic modelling by means of a simplified energy balance at the leaf level. This model was then used in an exploratory way to identify the bioclimatological factors most significant in relation to the protective effect of canopy heterogeneity.

\section{Materials and methods}

\subsection{Study site and plant material}

The field experiment was carried out in the Experimental Station of Choquenaria, of the Agronomy Faculty of the San Andres University of La Paz (Bolivia). The geographical location ( $16^{\circ} 41^{\prime} \mathrm{S}$, $\left.68^{\circ} 16^{\prime} \mathrm{W}\right)$ and the altitude ( $3850 \mathrm{~m}$ a.s.l.) make this site representative of the Andean climate where quinoa was domesticated. The soil is loamy (clay: $15 \%$, loam: $45 \%$, sand: $40 \%$ ) with a mean depth between 35 and $45 \mathrm{~cm}$. During the 20012002 crop cycle (October-March), the total rainfall was $315 \mathrm{~mm}$ with 54 rainy days and a daily maximum of $27.4 \mathrm{~mm}$. During the same period, air temperature at $1.5 \mathrm{~m}$ height showed absolute and mean daily minimum values of respectively -2.3 and $+1.7^{\circ} \mathrm{C}$, and absolute and mean daily maximum values of respectively +22.5 and $+16.0{ }^{\circ} \mathrm{C}$. Night air temperature at $1.5 \mathrm{~m}$ height was negative on 9 days, while data registered at $0.5 \mathrm{~m}$ showed negative values on 25 days.

Two quinoa (C. quinoa Willd.) cultivars of contrasted plant heterogeneity were compared: Surumi, a selected hybrid released in 1997 by IBTA (former Bolivian public agricultural research institute), and Blanca de Yanamuyu (hereafter called Blanca), a local landrace supposed to be genetically more heterogeneous than the selected hybrid. The experimental plots were located in the middle of a 2 ha flat experimental field sown with quinoa, providing a fetch distance sufficient against any advective effect. The two cultivar plots were adjacent and consisted of 3 rows, $5 \mathrm{~m}$ long and $0.5 \mathrm{~m}$ apart, in each cultivar. In this row crop, the plant canopy remained incomplete throughout the crop cycle as quinoa plants covered less than $75 \%$ of the ground area at their maximum growth. Crop sowing was on 18 October 2001, with crop emergence 5 days later, and final harvest at 147 DAE (days after emergence) for Surumi and 168 DAE for Blanca. Mean values of linear plant density at the beginning of the measurement period were similar in the two cultivars, with 70.6 plants $\mathrm{m}^{-1}$ for Surumi and 77.8 plants $\mathrm{m}^{-1}$ for Blanca. By the time of final harvest however, these values had gone to 36.7 and 62.3 plants $\mathrm{m}^{-1}$ for Surumi and Blanca respectively, due to differential mortality in the two cultivars, possibly due to high susceptibility to frost and hail in the selected cultivar Surumi.

\subsection{Field data collection}

Fine copper-constantan thermocouples with a $0.05{ }^{\circ} \mathrm{C}$ sensitivity were used to measure the surface temperature of the upper mature leaf in 16 individual plants of the central row in each cultivar plot. The thermocouples were attached on the lower side of the leaves by mean of a porous adhesive strip and their arrangement controlled twice a day. Air temperature at 5 , $10,20,50$ and $100 \mathrm{~cm}$ height was measured with the same type of copper-constantan thermocouples placed below small white-painted radiation shields within the central row in the Surumi plot.

Meteorological conditions were recorded at the centre of the experimental plot. Incoming solar radiation was measured with a SP1110 pyranometer (Sky Instruments), air temperature and humidity with a HMP45C sensor (Campbell Scientific), and wind speed with an A100 R switching anemometer (Campbell Scientific). Leaf temperature and meteorological data were automatically registered at $5 \mathrm{~min}$ intervals and averaged over $30 \mathrm{~min}$ periods before recording in a data logger (CR21X, Campbell Scientific). The night period was considered from 20:00 to 06:30. Data collection took place from 58 DAE, once the plants were vigorously established, until 139 DAE, when most plants showed advanced leaf senescence.

The height of the 32 plants equipped with thermocouples was measured weekly throughout the crop cycle, considering the main stem from the soil surface up to the extremity of the stem, or the panicle once it has emerged. Leaf area per plant $\left(A, \mathrm{~cm}^{2}\right)$ was calculated from the empirical allometric relation between leaf area and leaf number on the main stem $\left(L_{M S}\right)$ established in the same field with the same varieties in 2002-2003

$$
A=12.94 L_{M S}-111.66 \quad\left(R^{2}=0.69, n=132\right)
$$

Neither a difference between the two varieties, nor a significant effect of the phenological stage was found in this relation. In the 2001-2002 leaf temperature experiment, the number of leaves on the main stem of the 16 plants of each variety equipped with thermocouples was counted on 8 days $(52,58,65,72,80,87,101$, $108 \mathrm{DAE}$ ) and linearly interpolated for the other days. These data were used to estimate the leaf area per plant from the linear correlation established in 2002-2003. For each variety, the leaf area index $\left(\mathrm{m}^{2}\right.$ leaf area $/ \mathrm{m}^{2}$ soil) on each day was then calculated multiplying the mean leaf area per plant by the plant density observed for this variety. 


\subsection{Modelling approach}

An energy balance approach was used to model leaf temperatures within the quinoa canopy characterized by its height $\left(z_{h}\right)$ and its leaf area index $\left(L_{0}\right)$. Vertical heterogeneity in leaf temperature was considered between two specific leaves: one located at the top to the tallest plant and the other at the top of the shortest plant within the row. Both leaves were assumed to be horizontal. Applying the energy balance equation to herbaceous plants at night, the heat storage term as well as the transpiration flux can be neglected, the first one because of the small biomass of the leaf blades, the second one because leaf stomata are closed at night. Then, the energy balance of a leaf at a height $z$ within the canopy is written as

$\varepsilon\left[R_{l}(z)-2 \sigma T_{L}^{4}(z)\right]=2 \rho c_{p} g_{b}\left[T_{L}(z)-T_{a}(z)\right]$

where $\varepsilon$ is leaf emissivity, $R_{l}$ is the sum of the incoming long wave radiation on both sides of the leaf, $\sigma$ is the Stefan-Boltzmann constant, $T_{L}$ is leaf temperature, $\rho$ is the air density, $c_{p}$ is the specific heat of air at constant pressure, $g_{b}$ is leaf boundary layer conductance, and $T_{a}$ is air temperature at leaf height. Dew (or rime) deposition on leaves occurs when leaf temperature falls below dew point temperature. When this deposition occurs, a term of latent heat flux ( $\lambda E$ ) should be added to the right hand side of the energy balance equation (Eq. (2))

$\lambda E=2\left(\frac{\rho c_{p}}{\gamma}\right) g_{b}(z)\left[e^{*}\left[T_{L}(z)\right]-e_{a}(z)\right]$

where $\gamma$ is the psychrometric constant, $e^{*}(T)$ is the saturated vapour pressure at temperature $T$ and $e_{a}$ is the vapour pressure of the air. Linearising $T_{L}^{4}$ and $e^{*}\left(T_{L}\right)$ the energy balance equation can be solved with respect to $T_{L}$ (Kreith and Sellers, 1975; Monteith, 1981) and yields, without dew deposition,

$T_{L}(z)=T_{a}(z)+\frac{\varepsilon R_{l}(z)-2 \varepsilon \sigma T_{a}^{4}(z)}{8 \varepsilon \sigma T_{a}^{3}(z)+2 \rho c_{p} g_{b}(z)}$

and with dew or rime deposition,

$T_{L}(z)=T_{a}(z)+\frac{\varepsilon R_{l}(z)-2 \varepsilon \sigma T_{a}^{4}(z)-2 \rho c_{p} g_{b}(z) D_{a}(z) / \gamma}{8 \varepsilon \sigma T_{a}^{3}(z)+2 \rho c_{p} g_{b}(z)(1+s / \gamma)}$

where $D_{a}$ is air vapour pressure deficit and $s$ is the slope of the saturation vapour pressure curve at the temperature of the air. The practical calculation of leaf boundary layer conductance is given in Appendix A. In order to simplify these general expressions, some approximations were made: as $T_{a}(z)$ was expressed in Kelvin (with power 3 or 4 ), it was approximated by the air temperature at the reference height $T_{a}$ (the error involved being relatively small), and since no evaporation takes place at night, air saturation deficit $D_{a}(z)$ was taken to be equal to that at the reference height $D_{a}$. Consequently the difference in leaf temperature $\Delta T_{L}$ between the upper leaf of the smallest plant (with height $z_{s}$ ) and the upper leaf of the tallest plant (with height $z_{t}=z_{h}$ ) can be expressed as a function of the difference in air temperature between the same heights $\Delta T_{a}=T_{a}\left(z_{s}\right)-T_{a}\left(z_{t}\right)$ as follows

$\Delta T_{L}=T_{L}\left(z_{s}\right)-T_{L}\left(z_{t}\right)=\Delta T_{a}+F\left(z_{s}\right)-F\left(z_{t}\right)$

with

$F(z)= \begin{cases}\frac{\varepsilon R_{l}(z)-2 \varepsilon \sigma T_{a}^{4}}{8 \varepsilon \sigma T_{a}^{3}+2 \rho c_{p} g_{b}(z)} & \text { if } T_{L}(z) \geq T_{d p}(z) \\ \frac{\varepsilon R_{l}(z)-2 \varepsilon \sigma T_{a}^{4}-2 \rho c_{p} g_{b}(z) D_{a} / \gamma}{8 \varepsilon \sigma T_{a}^{3}+2 \rho c_{p} g_{b}(z)(1+s / \gamma)} & \text { if } T_{L}(z)<T_{d p}(z)\end{cases}$

$T_{d p}$ being the dew point temperature of the air. With respect to the radiative term $R_{l}(z)$, the upper side of an horizontal leaf located within the canopy was assumed to receive a weighted value of the radiations emitted by the atmosphere and by the canopy elements, and on its lower side the radiation emitted by the canopy (soil surface and foliage). If $\omega(z)$ represents the sky view factor at height $z$ within the canopy, the long wave radiation incoming on the leaf (both sides) is written as

$R_{l}(z)=\omega(z) R_{a}+[2-\omega(z)] \varepsilon \sigma T_{a}^{4} \quad 0<\omega(z)<1$

where $R_{a}$ is the downward long wave radiation from the sky. For convenience the canopy was assumed to be approximately at the temperature of the air. The error generated by this approximation is negligible since canopy and air temperatures at night are not very different when expressed in Kelvin. By analogy with the extinction law of solar radiation within canopies (Monsi and Saeki, 1953), the value of $\omega(z)$ was made a decreasing exponential function of the leaf area $L(z)$ cumulated from the top of the canopy down to the height $z$ of the leaf

$\omega(z)=\exp [-\beta L(z)]$

Since it is defined for night conditions, the empirical extinction coefficient $\beta$ is not exactly the same as the extinction coefficient for solar radiation in the daytime. It depends on structural characteristics of the canopy like leaf distribution, leaf form and inclination, and its value was determined by trial and error using the temperature difference between the upper leaf of the tallest plant and the upper leaf of the smallest one. The three nights with the lowest atmospheric radiation were chosen among the data set to carry out this determination. The value retained for $\beta$ was 1 , which ties up with the values of $0.3-1.5$ commonly found for the extinction coefficient for solar radiation (Jones, 1992; Ruiz and Bertero, 2008). Assuming leaf area to be uniformly distributed with height, function $L(z)$ was parameterized as

$L(z)=\frac{L_{0}\left(z_{h}-z\right)}{z_{h}}$

where $L_{0}$ is canopy leaf area index (LAI) and $z_{h}$ is canopy height. Incoming long wave radiation $R_{a}$ was estimated by means of a formula adapted to the specific conditions of the Bolivian Altiplano by Lhomme et al. (2007). This formula, derived from the one proposed by Brutsaert (1982), is written as

$R_{a}=\mu\left(\frac{e_{a}}{T_{a}}\right)^{1 / 7} \sigma T_{a}^{4} \quad \mu=1.18(-0.34 v+1.37)$

where $e_{a}$ is the air humidity at screen level in hPa, $T_{a}$ is air temperature in $\mathrm{K}$, and $v$ represents the mean ratio of $R_{s} / R_{s 0}\left(R_{s}\right.$ : the incoming solar radiation, $R_{s 0}$ : the solar radiation received under clear-sky conditions) calculated for the afternoon of the previous day (between 14:00 and 16:30). The parameter $\mu$ is directly linked to sky cloudiness: it increases with cloudiness roughly from 1.2 (clear sky) to 1.6 (completely overcast sky).

\subsection{Statistical and sensitivity analyses}

The predictive capacity of the model was analysed with three statistical properties: the bias $(B)$, the root mean square error (RMSE), and the coefficient of determination of the regression between estimated and measured values $\left(R^{2}\right)$. The bias shows to what extent data are over- or under-estimated, while RMSE measures the model accuracy, and $R^{2}$ the proportion of variance in the measured values explained by the model.

In order to identify the factors most critical in the leaf energy balance, the model sensitivity to changes in weather and canopy factors was tested. In the model, canopy structure is essentially represented by canopy height $\left(z_{h}\right)$ and leaf area index $\operatorname{LAI}\left(L_{0}\right)$, and atmospheric conditions by wind speed $\left(u_{a}\right)$, sky cloudiness $(\mu)$, 


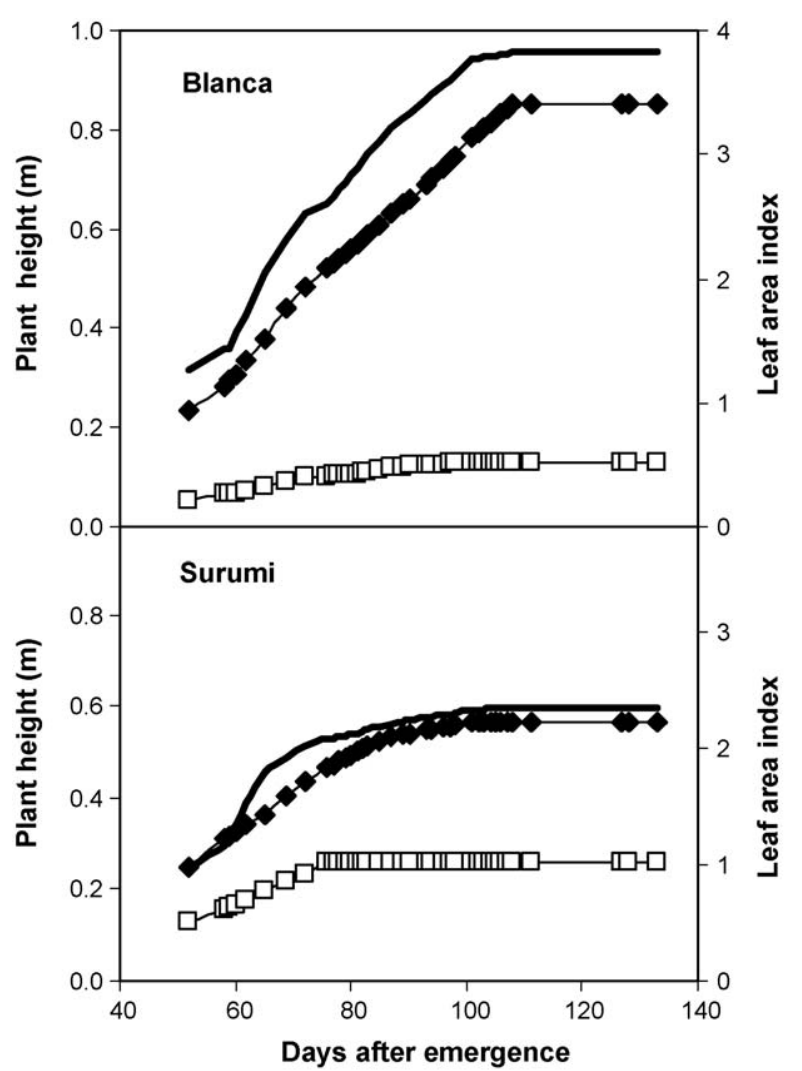

Fig. 1. Seasonal variation in the leaf area index (bold line) and the height of the smallest (white symbols) and tallest (black symbols) plant in the Blanca and Surumi quinoa plots.

relative air humidity $\left(R H_{a}\right)$ and air temperature $\left(T_{a}\right)$. The model was run successively varying the value of one parameter, all other parameters being kept equal. The basic values used in the simulations were: $z_{h}=1 \mathrm{~m}, L_{0}=4, \mu=1.3, R H_{a}=90 \%, u_{a}=1 \mathrm{~m} \mathrm{~s}^{-1}$, $T_{a}=-5{ }^{\circ} \mathrm{C}$, which corresponds to situations of high frost risk observed in the field. The output of the model was the difference in leaf temperature $\Delta T_{L}$ (Eq. (6)) between two levels within the canopy, specifically the upper leaf of the smallest plant and that of the tallest plant within a crop row. Three hypothetical conditions of vertical heterogeneity in the crop row were considered, according to the difference in the height of the smallest plant $z_{s}$ relative to that of the tallest plant $z_{h}$, namely: $z_{s}=0.25 z_{h}$,

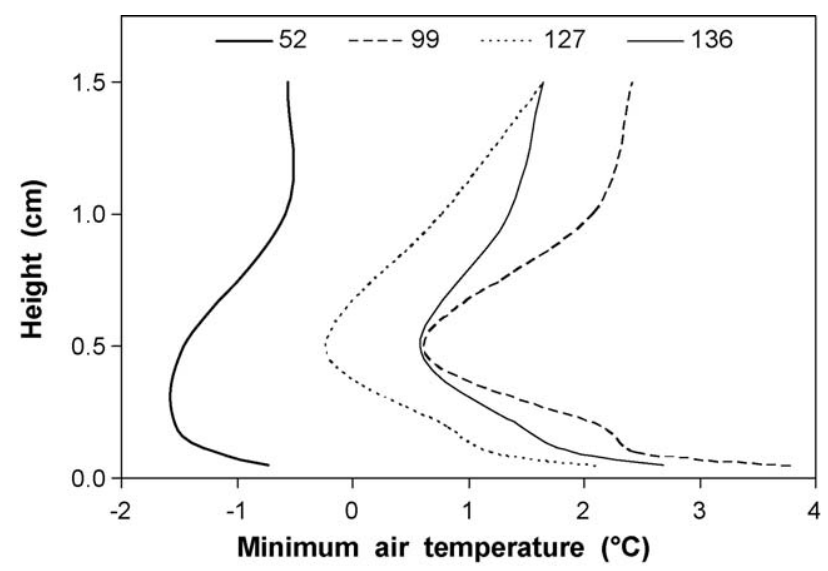

Fig. 2. Vertical profiles of minimum air temperature registered in a quinoa stand on 4 different nights (numbers on the curves indicate days after emergence).

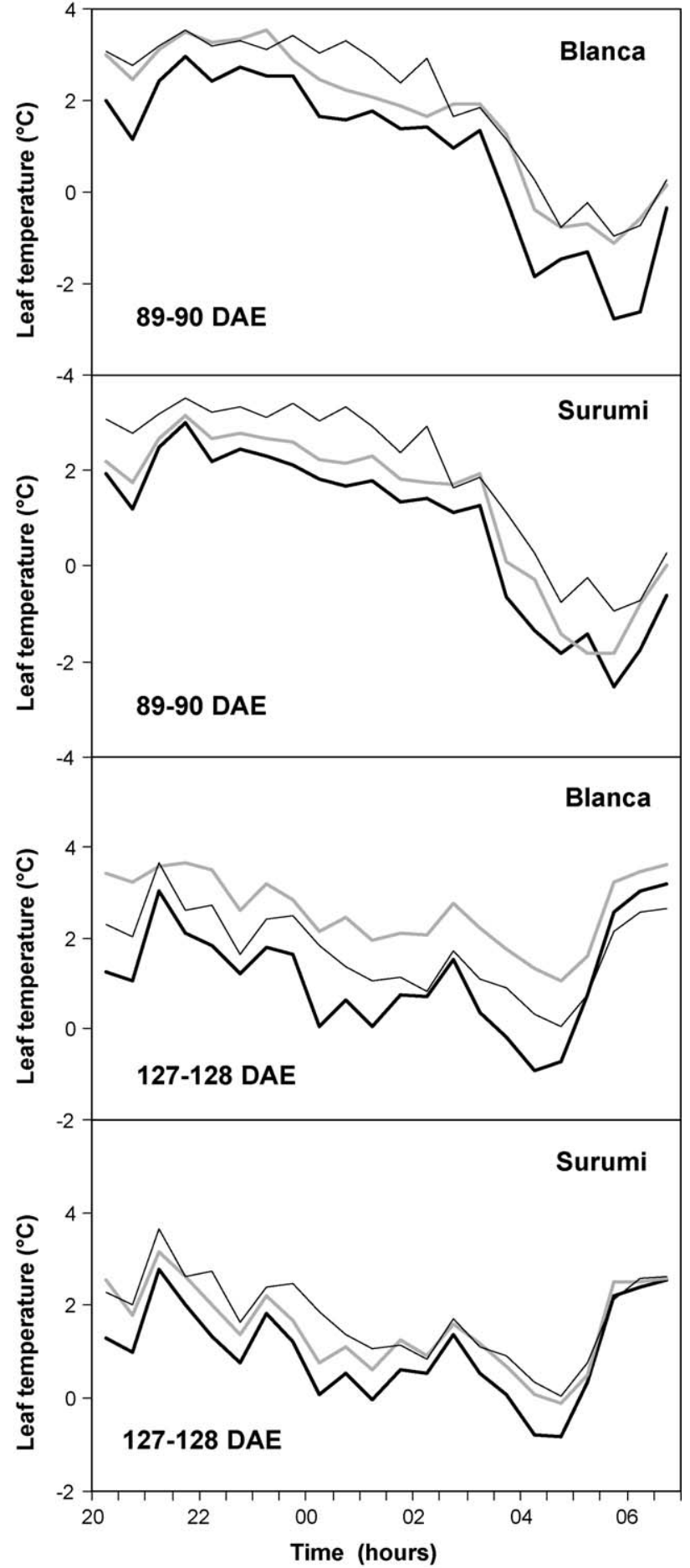

Fig. 3. Example of variation in the temperature of the upper leaves of the smallest (grey line) and tallest (dark line) plants in the Blanca and Surumi quinoa plots, on the nights of 89-90 DAE and 127-128 DAE. The thin lines show air temperature at $1.5 \mathrm{~m}$ height.

$z_{s}=0.50 z_{h}$, and $z_{s}=0.75 z_{h}$, for an heterogeneous, an intermediate, and an homogeneous canopy respectively. Air temperature within the canopy $T_{a}(z)$ and the difference $\Delta T_{a}=T_{a}\left(z_{s}\right)-T_{a}\left(z_{h}\right)$ can be predicted only through a rather complex micrometeorological model, which is beyond the scope of the present study. In the sensitivity analysis, an arbitrary value of $\Delta T_{a}$ was introduced. It was calculated from the mean negative gradient of air temperature observed during the experiment within a fully established quinoa canopy (see Fig. 2) during calm and clear nights. The value retained 


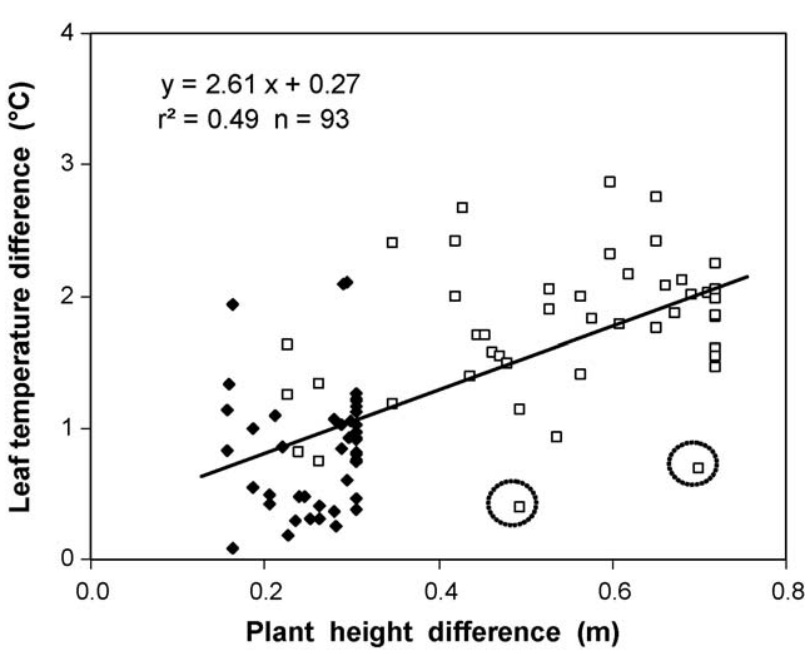

Fig. 4. Regression line between maximum difference in night leaf temperature and the corresponding difference in plant height observed during 33 nights in the Blanca (white symbols) and Surumi (black symbols) cultivars of quinoa (two circled points were discarded from the regression).

for this gradient was $-2{ }^{\circ} \mathrm{C} \mathrm{m}^{-1}$, considering wind velocities lower than $3 \mathrm{~m} \mathrm{~s}^{-1}$.

\section{Results}

\subsection{Experimental results}

Fig. 1 shows that the difference in plant height between the smallest and the tallest plants was higher in Blanca than in Surumi (e.g. this difference was $53 \mathrm{~cm}$ in Blanca versus $28 \mathrm{~cm}$ in Surumi on 90 DAE, and $72 \mathrm{~cm}$ in Blanca versus $31 \mathrm{~cm}$ in Surumi on $128 \mathrm{DAE}$ ). This disparity in plant height heterogeneity among both varieties was maintained throughout the crop cycle, as the landrace Blanca always presented at the same time smaller and taller individuals than the selected cultivar Surumi.

The seasonal development of the crop canopy also influenced the vertical profiles of air temperature within the quinoa stand (Fig. 2). These profiles, registered on clear calm nights prone to radiative cooling, showed minimum values of air temperature at a height corresponding roughly to the upper part of the crop canopy (ca. $25 \mathrm{~cm}$ at $52 \mathrm{DAE}$ and $50 \mathrm{~cm}$ on later dates). At this height, air
Table 1

Mean values ( \pm standard error) of leaf temperature difference $\left(\Delta T_{L}\right)$ and leaf temperature of the smallest plant $\left(T_{\text {small }}\right)$ in the selected cultivar Surumi and the landrace cultivar Blanca.

\begin{tabular}{lrll}
\hline & \multicolumn{1}{l}{ Surumi } & Blanca & Paired $t$-test for means \\
\hline All nights & & & \\
$\Delta T_{L}\left({ }^{\circ} \mathrm{C}\right)$ & $0.31(0.02)$ & $0.97(0.02)$ & $P<0.001, n=762$ \\
$T_{\text {small }}\left({ }^{\circ} \mathrm{C}\right)$ & $3.15(0.08)$ & $3.93(0.08)$ & $P<0.001, n=762$ \\
Coldest nights & & & \\
$\Delta T_{L}\left({ }^{\circ} \mathrm{C}\right)$ & $0.17(0.08)$ & $1.18(0.06)$ & $P<0.001, n=63$ \\
$T_{\text {small }}\left({ }^{\circ} \mathrm{C}\right)$ & $-0.95(0.13)$ & $0.17(0.10)$ & $P<0.001, n=63$ \\
\hline
\end{tabular}

temperature could be up to $3{ }^{\circ} \mathrm{C}$ lower than that of the air close to the bottom of the canopy, at $5 \mathrm{~cm}$ height (see profile at $99 \mathrm{DAE}$ in Fig. 2), and $2{ }^{\circ} \mathrm{C}$ lower than that registered at screen height.

Fig. 3 illustrates the changes in air temperature at reference height $(1.5 \mathrm{~m})$, and in upper leaf temperature of the smallest and tallest plants within the canopy during two typical cold nights in both cultivar plots. In general, air temperature decreased progressively in the first part of the night and dropped more abruptly by the end of the night, with the lowest values commonly reached just before sunrise. This overnight pattern of air temperature variations is typical of the radiative cooling process occurring at high altitude under calm and cloudless conditions. Leaf temperature variations paralleled those in air temperature, at a level generally lower by $1{ }^{\circ} \mathrm{C}$ in tall plants. This corresponded to a period of negative leaf temperatures of roughly $2 \mathrm{~h}$ on 89-90 DAE, and $1 \mathrm{~h}$ on 127-128 DAE. The exact duration as well as the absolute minimum temperature reached during the night depended on the relative position of the plants within the canopy, with the tallest plants enduring lower leaf temperatures for a longer duration than the smallest ones. This was particularly apparent in Blanca where leaf temperature of small plants remained higher than that of tall plants by as much as $2{ }^{\circ} \mathrm{C}$, a difference enough for the small plants to escape from radiative freezing (see data of 127-128 DAE in Fig. 3). Comparing tall plants of the two varieties, their leaf temperatures did not appear very different, suggesting that the upper part of the whole field canopy experienced more or less the same temperature, while small plants from the lower part of the canopy benefited from a sheltering effect.

The relation between the difference in leaf temperature and that in plant height within the canopy is shown in Fig. 4 which

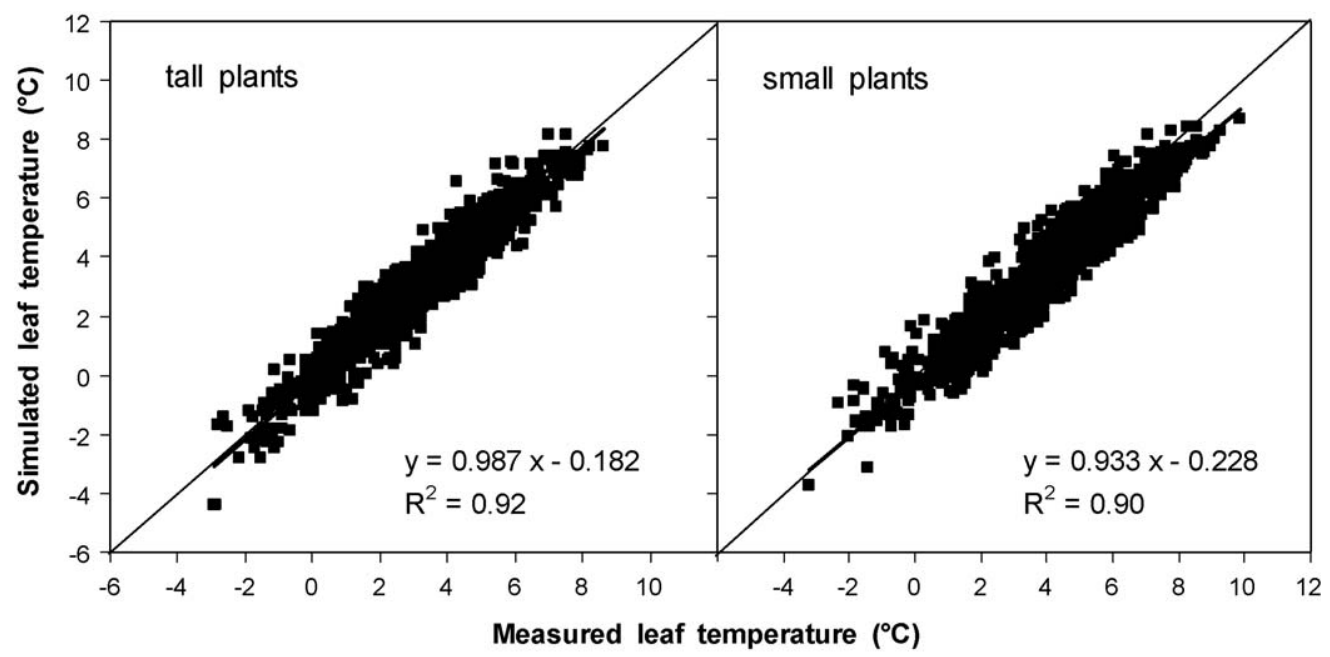

Fig. 5. Comparison between measured and simulated leaf temperature at night in tall and small plants of the two studied cultivars of quinoa $(n=978$, the oblique lines show the $1: 1$ line). 
Table 2

Statistical comparison of estimated and measured values of leaf temperature $(T)$ and leaf temperature difference $\left(\Delta T_{L}\right)$ between tall and small plants in two quinoa cultivars ( $B$ : bias; RMSE: root mean square error; $R^{2}$ : determination coefficient of the regression line).

\begin{tabular}{llll}
\hline & $B$ & RMSE & $R^{2}$ \\
\hline Surumi, $n=489$ & & & \\
$T_{\text {tall }}\left({ }^{\circ} \mathrm{C}\right)$ & -0.20 & 0.63 & 0.91 \\
$T_{\text {small }}\left({ }^{\circ} \mathrm{C}\right)$ & -0.18 & 0.63 & 0.91 \\
$\Delta T_{L}\left({ }^{\circ} \mathrm{C}\right)$ & -0.03 & 0.20 & 0.01 \\
Blanca, $n=489$ & & & \\
$T_{\text {tall }}\left({ }^{\circ} \mathrm{C}\right)$ & -0.25 & 0.63 & 0.91 \\
$T_{\text {small }}\left({ }^{\circ} \mathrm{C}\right)$ & -0.82 & 0.54 & 0.93 \\
$\Delta T_{L}\left({ }^{\circ} \mathrm{C}\right)$ & -0.57 & 0.29 & 0.13 \\
\hline
\end{tabular}


Fig. 6. Sensitivity of the temperature difference between the upper leaf of tall and small plants to changes in maximum canopy height (a), leaf area index (b), wind speed (c), sky cloudiness (d), air humidity (e) and temperature (f). Reference conditions were as follows: $z_{h}=1 \mathrm{~m}, \mathrm{LAI}=4, \mu=1.3, R H_{a}=90 \%, u_{a}=1 \mathrm{~m} \mathrm{~s}{ }^{-1}, T_{a}=-5{ }^{\circ} \mathrm{C}$. Black, grey and white symbols represent heterogeneous, intermediate and homogeneous canopies respectively. 
plants in Blanca, and only $0.17^{\circ} \mathrm{C}$ higher in Surumi. The sheltering effect resulted in a mean minimum leaf temperature of $0.17^{\circ} \mathrm{C}$ in small plants of Blanca, significantly higher than the mean value of $-0.95{ }^{\circ} \mathrm{C}$ registered in the neighbouring plot of Surumi. These cold nights were also those with significantly lower wind (mean $\pm \mathrm{SE}$ : $0.47 \pm 0.07 \mathrm{~m} \mathrm{~s}^{-1}$ versus $1.15 \pm 0.04 \mathrm{~m} \mathrm{~s}^{-1}$ for the whole set of nocturnal values), a situation which promotes air stability and vertical temperature stratification.

\subsection{Model validation and predictions}

The results of the statistical comparison between measured and simulated leaf temperature at two canopy levels for both quinoa cultivars and 33 nights are presented in Fig. 5 and Table 2. The statistical analyses refer only to situations when wind velocities were higher than $0.2 \mathrm{~m} \mathrm{~s}^{-1}$. In fact, in situations of very low wind speed, leaf temperatures of tall plants appeared clearly underestimated by the model. This discrepancy occurred because convective transfers under low wind conditions are inadequately formulated in our simplified model in which wind profiles above and within the canopy do not account for stability corrections (see Appendix A). Furthermore, the performances of the anemometer are limited when the wind becomes weak: the manufacturer indicates a stalling wind speed of $0.2 \mathrm{~m} \mathrm{~s}^{-1}$, which means that the recorded data poorly represent situations of very low wind. Excluding these particular situations gives a subset of $88 \%$ of the original data set $(n=978)$ for which the model generally underestimated the observations with biases ranging from -0.18 to $-0.82{ }^{\circ} \mathrm{C}$ for leaf temperatures, and from -0.03 to $-0.57{ }^{\circ} \mathrm{C}$ for the leaf temperature difference between tall and small plants (Table 2 ). The underestimation, which appeared higher in Blanca than in Surumi, was the result of neglecting the air temperature gradient within the canopy since $T_{a}(z)=T_{a}$ in Eqs. (4) and (5). The RMSE for leaf temperatures were between 0.54 and $0.66^{\circ} \mathrm{C}$, while those for the leaf temperature difference between tall and small plants were between 0.20 and $0.29^{\circ} \mathrm{C}$. These error values were lower than leaf temperature differences measured in the field for Blanca, but higher than those measured in Surumi (Table 1 ). The $R^{2}$ values between measured and simulated leaf temperatures were always higher than 0.90 , while those for the leaf temperature differences were much lower though statistically significant in Blanca. Thus, the model appears suitable for simulating relatively high leaf temperature differences in an heterogeneous canopy like that of Blanca. But its accuracy becomes insufficient for the much smaller temperature differences observed in the more homogeneous canopy of Surumi.

The sensitivity of simulated leaf temperature difference $\left(\Delta T_{L}\right)$ to incremental changes in weather and canopy variables is presented in Fig. 6, considering three levels of canopy vertical heterogeneity. For all the variables examined, the leaf temperature difference between tall and small plants was approximately proportional to the canopy vertical heterogeneity, with lowest temperature difference in the most homogeneous canopy $\left(z_{s}=0.75 z_{h}\right)$. Regarding the canopy architecture (Fig. 6a and b), increasing canopy height $\left(z_{h}\right)$ and LAI increased leaf temperature difference. This relation was continuous in the case of $z_{h}$, while it reached a plateau for LAI higher than 3 . It should be noted that LAI values of 3 represent an upper limit in farmers' fields in the northern altiplano of Bolivia. Regarding atmospheric factors, sky cloudiness $(\mu)$ showed a greater influence on $\Delta T_{L}$ than wind speed $\left(u_{a}\right)$, air temperature $\left(T_{a}\right)$ or air humidity $\left(R H_{a}\right)$ (Fig. $\left.6 \mathrm{c}-\mathrm{f}\right)$. The effect of sky cloudiness was high for values less than 1.3 (clear sky) and decreased progressively as the sky becomes more cloudy. Changes in wind speed apparently had little impact on $\Delta T_{L}$, but this could be an artefact due to the modelling procedure (see Section 4). As regards air temperature and humidity (Fig. 6e and f), their changes had little effect on $\Delta T_{L}$ as long as dew point temperature was not reached. For relative humidity $R H_{a}$ higher than $90 \%$, or air temperature $T_{a}$ lower than $-6{ }^{\circ} \mathrm{C}$ (the other parameters being kept at their reference level), dew begins to deposit on the leaves and this condensation releases heat that reduces the temperature difference $\Delta T_{L}$ (Fig. 6e and f).

\section{Discussion}

\subsection{Temperature gradients within canopies}

Under clear-sky conditions at night, the upper leaf temperature of small plants of quinoa was up to $2-3^{\circ} \mathrm{C}$ higher than that of taller plants growing above them (Fig. 3 and Table 1). This difference is similar to that registered during night cooling on shaded coffee plants growing under taller trees in Brazil (Caramori et al., 1996), or on Metrosideros polymorpha seedlings sheltered by Acacia koa in Hawaï (Scowcroft et al., 2000). It also compares to temperature gains observed during night cooling under artificial shelters like shade cloths (Nina Laura et al., 2004; Scowcroft et al., 2000). Finally, it has the same magnitude as instantaneous leaf temperature differences measured before sunrise between neighbouring maize plants in the field (Chelle, 2005). The similarity of the leaf temperature gain due to sheltering either in annual quinoa fields or in perennial plantations under shade trees suggests that temperature differences within the canopy are dominated by the extent of cover of the sheltering canopy more than by the type, either herbaceous or woody, of the plants (see below the discussion about the sky view factor).

On clear and calm nights during the crop cycle, vertical profiles in air temperature reveal that the air layer in the upper part of the quinoa canopy was at a lower temperature than the layers above and below it (Fig. 2). Such profiles showing temperature changes up to $4{ }^{\circ} \mathrm{C}$ over $1 \mathrm{~m}$ height were observed over bare soil surfaces or low grass fields, but only transiently since the unstable warm air layer near the ground finally mixes with the more stable cold layer above it (Lake, 1956; Oke, 1970). In the case of relatively sparse and tall canopies such as quinoa, these inverted profiles of night air temperature are maintained because unshaded upper plants represent a sink of heat due to their radiative deficit, thus impeding the equalization of air temperatures within the canopy. The layer of cold air at the top of the canopy is due to high radiation losses by upper plant parts, which explains the common observation of quinoa plants starting to freeze from their upper part. Apart from organ destruction by freezing, non-lethal low temperatures concentrated at that level could affect physiologically active leaves and growing panicles, thus threatening the potential for growth and development of the plants (Bois et al., 2006; Jacobsen et al., 2005). Visible plant stress in the day following a cold night is common in quinoa fields over the altiplano where sun irradiance rises rapidly in the morning. As outlined by Jordan and Smith (1995a), radiation frosts occur because of clear skies at night and these nights are commonly associated with clear skies and high sunlight levels in the following morning. This simultaneous occurrence of low tissue temperatures with high incident sunlight has been shown to have a particularly severe effect on photosynthetic functions. While quinoa plants are able to maintain high photochemical efficiency in case of physiological stress (Bosque Sanchez et al., 2003; Winkel et al., 2002), it may be that the combination of low night temperature and high morning irradiance temporarily exceeds these physiological tolerance capacities. In that situation, sheltering by tall plants could be important since, as shown by Langvall and Orlander (2001) and Orlander (1993) in conifer seedlings, higher night air temperature near the ground and shading the day after a frost event reduce visible damage and low-temperature induced photoinhibition in small plants. 
The assessment of sheltering in heterogeneous quinoa crop should also consider the diversity of crop practices affecting the canopy structure. Traditionally, quinoa is sown in rows, in clumps, or broadcasted, and sometimes, though rarely, grown in association with other crops (Izquierdo Fernández et al., 2001; National Research Council, 1989). In the coldest and most arid regions of the Bolivian altiplano, which are also those of major quinoa production, clump planting in pure stands is generalized. Bandaru et al. (2006) demonstrate that growing sorghum in clumps is beneficial in semiarid environments since crop water use is reduced by limited vegetative growth and reduced sunlight penetration within the plant clumps. In the case of quinoa, it would be interesting to test if clump planting results in useful benefits against both drought and frost (Bertero, personal communication). This sowing practice obviously influences the crop architecture and microclimate in a different way than sowing in rows, particularly because the low clump density commonly observed in farmers' fields should influence the vertical stratification of night air and leaf temperature. Deficit irrigation is another, yet experimental, strategy considered for stabilizing quinoa production in the semiarid altiplano (Geerts et al., 2008a,b). Contrary to full irrigation, deficit irrigation does not seek to maximize plant height and leaf area and, thus, probably maintains a relatively high plant heterogeneity within the field. By sustaining the growth of some of the plants within the field, deficit irrigation could promote the sheltering of small plants by taller ones, thus reconciling the objectives of stabilizing crop yield through plant watering and maintaining crop frost tolerance through canopy heterogeneity.

\subsection{Relevant bioclimatological factors}

Our simplified energy balance model at the leaf level identified crop structure parameters like canopy vertical heterogeneity and leaf area index as the most relevant for the development of leaf temperature gradients within the canopy. The height of an individual plant within the canopy determines the proportion of the total LAI situated above it. The height and LAI components of the canopy structure determine the value of the sky view factor at the leaf level $(\omega(z)$ in Eq. (9)). In multi-layer forests, frost damage to tree seedlings decreases with decreasing sky view factor (Groot and Carlson, 1996), which suggests a beneficial influence of a dense canopy for seedling survival after frosty nights. Blennow (1998) modelling night air temperature in partially and clear felled forest found that the sky view factor explains most of the variation in minimum air temperature for clear and calm nights. This author states that variables used to model night temperature variations at local and regional scales may also be applied in microscale models of near-ground temperature. Although our model based on leaf energy balance differs intrinsically from statistical regression models of topoclimate, it is worth noting that the sky view factor appears critical in minimum temperature modelling by both approaches.

Among atmospheric factors, sky cloudiness played a greater role than air temperature and humidity, with low values of cloudiness most favourable to frost. As pointed by Jordan and Smith (1995a) the coldest leaf temperatures result from the combined effects of low air temperature at plant height and low sky infrared radiation on calm, clear nights. These authors state that sky cloudiness has more influence on plant freezing risk than night air temperature, a result corroborated by the sensitivity analysis of our model. Air temperature and humidity strongly affect the response of individual quinoa plants to low temperatures (Jacobsen et al., 2005). But their impact on leaf temperature gradients within a quinoa canopy appeared lower than that of canopy structural parameters like canopy height, plant height heterogeneity, and leaf area index. The sensitivity analysis reveals a breakdown in the effect of air temperature and humidity when dew point temperature is reached: leaf temperature differences decreased rapidly when air humidity exceeded $90 \%$ or air temperature fell below $-6{ }^{\circ} \mathrm{C}$ (Fig. $6 \mathrm{e}$ and $\mathrm{f}$ ). The resulting decrease in leaf temperature difference between small and tall quinoa plants fits the equalizing of the temperature profile near the ground mentioned by Lake (1956) in situations of dew deposition. This author adds that dew deposition occurs periodically at intervals between 40 and $60 \mathrm{~min}$, and results from a breakdown of the inverted density distribution in the air. Our observations of night air temperature profiles (Fig. 2) show that inverted air density distribution is frequent in quinoa fields. Yet, dew deposition remains exceptional on the Andean highlands where air humidity is generally low, particularly on clear and calm nights (Garcia et al., 2003; Geerts et al., 2006). Regarding wind speed, its apparently small impact on $\Delta T_{L}$ probably results from considering a constant gradient of air temperature within the canopy while, in reality, this gradient tends to vanish as wind speed increases. Moreover, our simplified model does not account for the mixture of free and forced convection existing on calm nights, thus leading to uncertainties about the actual influence of wind speed on $\Delta T_{L}$.

\subsection{Concluding remarks}

Continuous data collection throughout an entire quinoa crop cycle showed that, under field conditions prone to nocturnal cooling, leaf temperature gradients up to $2.6{ }^{\circ} \mathrm{C} \mathrm{m}^{-1}$ appeared within the canopy of a traditional quinoa landrace. In most cases, this significant leaf temperature difference would be sufficient to allow the lower part of the crop canopy to escape from lethal freezing. Leaf temperature gradients resulted from a sheltering effect provided by tall plants limiting the upward radiative energy losses from smaller plants beneath them. A simplified leaf energy balance model allows to adequately simulate these leaf temperature differences in the case of a vertically heterogeneous quinoa canopy. It should be valid for other crop species cultivated in fairly dense canopies where horizontal heterogeneity can be neglected. But in horizontally heterogeneous crops, with widely spaced or clumped planting, the model should be adapted to take account of the heat exchanges with the bare soil surface. The model sensitivity analysis reveals that among agroclimatic factors, high leaf area index, low sky cloudiness and low wind speed are the most important influences on the development of the sheltering effect. This protective effect could be an example of the functional role of crop diversity at the field level in the case of nocturnal frost. Jacobsen et al. (2005) showed that frost damage on quinoa crop production is greater when frost stress occurs at anthesis or during the early grain filling period, i.e. when leaves and buds showed the highest physiological susceptibility to frost and plants have reached their maximum growth. In that situation, sheltering by tall plants may protect small plants within the canopy against nocturnal cooling. Then, in case of serious damage to tall plants, these small plants could survive the isolated frost event, continue their growth and development, and finally contribute to grain yield, thus limiting the impact of frost. This mechanism related to asynchrony in growth between plants within the same field could be potentially beneficial for crop productivity under risky environments or low-input cropping systems (De Rouw, 2004; De Rouw and Winkel, 1998; Lambdon et al., 2003; Varga et al., 2004), in a way similar to that observed in several wild species (Bolmgren, 1998; Picó et al., 2002).

However, protection against frost events at night is only one aspect of the functional role of plant heterogeneity within the field: during daytime, small plants partially shaded by taller neighbours will necessarily be cooler and receive less solar radiation, two factors tightly related to leaf development in quinoa (Bertero, 
2001). Final quinoa seed yield is also affected negatively by low intercepted radiation and reduced plant height (Bertero and Ruiz, 2008; Bhargava et al., 2007a). Hence, the adaptive significance of morphological heterogeneity and asynchronous development within plant populations of quinoa landraces depends on a trade-off between wide stress adaptation and high biomass productivity which is difficult to solve in the case of low-input agriculture (Gliessman, 1990; Lefroy et al., 1999; Viglizzo and Roberto, 1998).

\section{Acknowledgements}

This research was funded by IRD and carried out in Bolivia in the frame of a scientific collaborative program between IRD-UR060 and the Faculty of Agronomy of the Universidad Mayor de San Andrés. It was part of the PhD and Masters theses of three of the coauthors. The authors are most grateful to Dr. Alejandro Bonifiacio (Fundation PROINPA, Bolivia) for providing the quinoa seeds, and to the reviewers for their valuable and helpful comments.

\section{Appendix A. Ancillary equations for the calculation of leaf boundary-layer conductance}

Leaf boundary-layer conductance is estimated from the following formulation

$g_{b}(z)=\alpha_{0} \sqrt{\frac{u(z)}{w}}$

where $u(z)$ is the wind speed at the height $z$ of the leaf and $w=$ $0.04 \mathrm{~m}$ is the leaf width with $\alpha_{0}=0.01 \mathrm{~m} \mathrm{~s}^{-1 / 2}$ (Choudhury and Monteith, 1988; Jones, 1999). The wind profile within the canopy is given by

$u(z)=u\left(z_{h}\right) \exp \left[-\alpha_{w}\left(1-\frac{z}{z_{h}}\right)\right]$

where $\alpha_{w}$ is the attenuation dimensionless coefficient equal to 1.3 (Cionco, 1972). Wind speed at canopy height $z_{h}$ is calculated from wind speed at the reference height $\left(u_{a}\right)$ assuming a logarithmic profile of wind speed above the canopy

$u\left(z_{h}\right)=\frac{u_{a} \ln \left[\left(z_{h}-d\right) / z_{0}\right]}{\ln \left[\left(z_{r}-d\right) / z_{0}\right]}$

The zero plane displacement height $d$ and the roughness length for momentum $z_{0}$ are determined following Choudhury and Monteith (1988)

$d=1.1 z_{h} \ln \left(1+X^{0.25}\right) \quad X=c_{d} L_{0}$

$z_{0}= \begin{cases}z_{0 s}+0.3 z_{h} X^{0.5} & 0<X<0.2 \\ 0.3 z_{h}\left(1-\frac{d}{z_{h}}\right) & 0.2<X<1.5\end{cases}$

where $c_{d}=0.2$ is the mean drag coefficient assumed to be uniform within the canopy. $z_{h}$ is the canopy height and $z_{0 s}$ is the roughness length of the soil surface taken to be equal to $0.01 \mathrm{~m}$.

\section{References}

Ayeneh, A., van Ginkel, M., Reynolds, M.P., Ammar, K., 2002. Comparison of leaf, spike, peduncle and canopy temperature depression in wheat under heat stress. Field Crops Research 79, 173-184.

Bandaru, V., Stewart, B.A., Baumhardt, R.L., Ambati, S., Robinson, C.A., Schlegel, A., 2006. Growing dryland grain sorghum in clumps to reduce vegetative growth and increase yield. Agronomy Journal 98, 1109-1120.
Bertero, H.D., 2001. Effects of photoperiod, temperature and radiation on the rate of leaf appearance in quinoa (Chenopodium quinoa Willd.) under field conditions. Annals of Botany 87, 495-502.

Bertero, H.D., Ruiz, R.A., 2008. Determination of seed number in sea level quinoa (Chenopodium quinoa Willd.) cultivars. European Journal of Agronomy 28, 186-194.

Bhargava, A., Shukla, S., Ohri, D., 2007a. Genetic variability and interrelationship among various morphological and quality traits in quinoa (Chenopodium quinoa Willd.). Field Crops Research 101, 104-116.

Bhargava, A., Shukla, S., Rajan, S., Ohri, D., 2007b. Genetic diversity for morphological and quality traits in quinoa (Chenopodium quinoa Willd.) germplasm. Genetic Resources and Crop Evolution 54, 167-173.

Black, C., Ong, C., 2000. Utilisation of light and water in tropical agriculture. Agricultural and Forest Meteorology 104, 25-47.

Blennow, K., 1998. Modelling minimum air temperature in partially and clear felled forests. Agricultural and Forest Meteorology 91, 223-235.

Bois, J.F., Winkel, T., Lhomme, J.P., Raffaillac, J.P., Rocheteau, A., 2006. Response of some Andean cultivars of quinoa (Chenopodium quinoa Willd.) to temperature: effects on germination, phenology, growth and freezing. European Journal of Agronomy 25, 299-308.

Bolmgren, K., 1998. The use of synchronization measures in studies of plant reproductive phenology. Oikos $82,411-415$.

Bosque Sanchez, H., Lemeur, R., Van Damme, P., Jacobsen, S.E., 2003. Ecophysiological analysis of drought and salinity stress of quinoa (Chenopodium quinoa Willd.). Food Reviews International 19, 111-119.

Brutsaert, W., 1982. Evaporation into the Atmosphere. Kluwer Academic Publishers, Dordrecht, The Netherlands, 299 pp.

Caramori, P.H., Androcioli, A., Leal, A.C., 1996. Coffee shade with Mimosa scabrella Benth for frost protection in southern Brazil. Agroforestry Systems 33, 205214.

Chelle, M., 2005. Phylloclimate or the climate perceived by individual plant organs: What is it? How to model it? What for?. New Phytologist 166, 781-790.

Choudhury, B.J., Monteith, J.L., 1988. A four-layer model for the heat budget of homogeneous land surfaces. Quarterly Journal of the Royal Meteorological Society $114,373-398$.

Cionco, R.M., 1972. A wind-profile index for canopy flow. Boundary-Layer Meteorology 3, 255-263.

De Chantal, M., Hanssen, K.H., Granhus, A., Bergsten, U., Lofvenius, M.O., Grip, H., 2007. Frost-heaving damage to one-year-old Picea abies seedlings increases with soil horizon depth and canopy gap size. Canadian Journal of Forest Research 37, 1236-1243.

De Rouw, A., 2004. Improving yields and reducing risks in pearl millet farming in the African Sahel. Agricultural Systems 81, 73-93.

De Rouw, A., Winkel, T., 1998. Drought avoidance by asynchronous flowering in pearl millet stands cultivated on-farm and on-station in Niger. Experimental Agriculture 34, 19-39.

Del Castillo, C., Winkel, T., Mahy, G., Bizoux, J.-P., 2007. Genetic structure of quinoa (Chenopodium quinoa Willd) from the Bolivian altiplano as revealed by RAPD markers. Genetic Resources and Crop Evolution 54, 897-905.

Feldhake, C.M., 2002. Forage frost protection potential of conifer silvopastures. Agricultural and Forest Meteorology 112, 123-130.

François, C., Bosseno, R., Vacher, J.J., Seguin, B., 1999. Frost risk mapping derived from satellite and surface data over the Bolivian Altiplano. Agricultural and Forest Meteorology 95, 113-137.

Garcia, M., Raes, D., Jacobsen, S.-E., 2003. Evapotranspiration analysis and irrigation requirements of quinoa (Chenopodium quinoa) in the Bolivian highlands. Agricultural Water Management 60, 119-134.

Garcia, M., Raes, D., Jacobsen, S.E., Michel, T., 2007. Agroclimatic constraints for rainfed agriculture in the Bolivian Altiplano. Journal of Arid Environments 71, 109-121.

Geerts, S., Raes, D., Garcia, M., Condori, O., Mamani, J., Miranda, R., Cusicanqui, J., Taboada, C., Yucra, E., Vacher, J., 2008a. Could deficit irrigation be a sustainable practice for quinoa (Chenopodium quinoa Willd) in the Southern Bolivian Altiplano? Agricultural Water Management 95, 909-917.

Geerts, S., Raes, D., Garcia, M., Del Castillo, C., Buytaert, W., 2006. Agro-climatic suitability mapping for crop production in the Bolivian Altiplano: a case study for quinoa. Agricultural and Forest Meteorology 139, 399-412.

Geerts, S., Raes, D., Garcia, M., Vacher, J., Mamani, R., Mendoza, J., Huanca, R., Morales, B., Miranda, R., Cusicanqui, J., Taboada, C., 2008b. Introducing deficit irrigation to stabilize yields of quinoa (Chenopodium quinoa Willd.). European Journal of Agronomy 28, 427-436.

Gliessman, S.R. (Ed.), 1990. Agroecology: Researching the Ecological Basis for Sustainable Agriculture. Springer-Verlag, Berlin, Germany, pp. 3-10.

Groot, A., Carlson, D.W., 1996. Influence of shelter on night temperatures, frost damage, and bud break of white spruce seedlings. Canadian Journal of Forest Research 26, 1531-1538.

Izquierdo Fernández, J.I., Mujica, A., Jacobsen, S.E., Marathée, J.P., Morón, C., 2001. Cultivos andinos. Versión 1.0. FAO, Santiago, Chile.

Jacobsen, S.E., Monteros, C., Christiansen, J.L., Bravo, L.A., Corcuera, L.J., Mujica, A., 2005. Plant responses of quinoa (Chenopodium quinoa Willd.) to frost at various phenological stages. European Journal of Agronomy 22, 131-139.

Jacobsen, S.E., Monteros, C., Corcuera, L.J., Bravo, L.A., Christiansen, J.L., Mujica, A., 2007. Frost resistance mechanisms in quinoa (Chenopodium quinoa Willd). European Journal of Agronomy 26, 471-475

Jones, H.G., 1992. Plants and Microclimate. Cambridge University Press, Cambridge, UK, 428 pp. 
Jones, H.G., 1999. Use of infrared thermometry for estimation of stomatal conductance as a possible aid to irrigation scheduling. Agricultural and Forest Meteorology 95, 139-149.

Jordan, D.N., Smith, W.K., 1995a. Microclimate factors influencing the frequency and duration of growth season frost for sub-alpine plants. Agricultural and Forest Meteorology 77, 17-30.

Jordan, D.N., Smith, W.K., 1995b. Radiation frost susceptibility and the association between sky exposure and leaf size. Oecologia 103, 43-48.

Kalberer, S.R., Wisniewski, M., Arora, R., 2006. Deacclimation and reacclimation of cold-hardy plants: current understanding and emerging concepts. Plant Science $171,3-16$.

Kreith, F., Sellers, W.D., 1975. General principles of natural evaporation. In: De Vries, D.A., Afgan, N.H. (Eds.), Heat and Mass Transfer in the Biosphere. Scripta Books, Washington DC, USA, pp. 207-227.

Lake, J.V., 1956. The temperature profile above bare soil on clear nights. Quarterly Journal of the Royal Meteorological Society 82, 187-197.

Lambdon, P.W., Hassall, M., Boar, R.R., Mithen, R., 2003. Asynchrony in the nitrogen and glucosinolate leaf-age profiles of Brassica: is this a defensive strategy against generalist herbivores? Agriculture, Ecosystems and Environment 97 205-214.

Langvall, O., Orlander, G., 2001. Effects of pine shelterwoods on microclimate and frost damage to Norway spruce seedlings. Canadian Journal of Forest Research $31,155-164$

Langvall, O., Ottonson Löfvenius, M., 2002. Effect of shelterwood density on nocturnal near-ground temperature, frost injury risk and budburst date of Norway spruce. Forest Ecology and Management 168, 149-161.

Lefroy, E.C., Hobbs, R.J., O'Connor, M.H., Pate, J.S. (Eds.), 1999. Agriculture as a Mimic of Natural Ecosystems. Kluwer Academic Publ., Dordrecht, The Netherlands, p. 504.

Leuning, R., 1988. Leaf temperatures during radiation frost Part II. A steady-state theory. Agricultural and Forest Meteorology 42, 135-155.

Leuning, R., Cremer, K.W., 1988. Leaf temperatures during radiation frost Part I. Observations. Agricultural and Forest Meteorology 42, 121-133.

Lhomme, J.P., Guilioni, L., 2004. A simple model for minimum crop temperature forecasting during nocturnal cooling. Agricultural and Forest Meteorology 123 $55-68$.

Lhomme, J.P., Vacher, J.J., 2002. Modelling nocturnal heat dynamics and frost mitigation in raised field systems of the Andean Altiplano. Agricultural and Forest Meteorology 112, 179-193.

Lhomme, J.P., Vacher, J.J., Rocheteau, A., 2007. Estimating downward long-wave radiation on the Andean Altiplano. Agricultural and Forest Meteorology 145, $139-148$.

Lhomme, J.P., Winkel, T., 2002. Diversity-stability relationships in community ecology: re-examination of the portfolio effect. Theoretical Population Biology 62, 271-279.

Monsi, M., Saeki, T., 1953. Über den Lichtfaktor in den Pflanzengesellschaften und seine Bedeutung für die Stoffproduktion. Japanese Journal of Botany 14, 22-52.

Monteith, J.L., 1981. Evaporation and surface temperature. Quarterly Journal of the Royal Meteorological Society 107, 1-27.

Morlon, P. (Ed.), 1996. Comprender la agricultura campesina en los Andes Centrales, Perú y Bolivia. IFEA, CBC, Lima, Peru, 495 pp.
National Research Council, 1989. Lost Crops of the Incas: Little-known Plants of the Andes with Promise for Worldwide Cultivation. National Academy Press, Washington, DC, USA, $427 \mathrm{pp}$

Nina Laura, J.P., Del Castillo, C., Winkel, T., 2004. Comportamiento de quinuas tradicional y mejorada frente al estrés térmico. CD-Rom: XI Congreso Internacional de Cultivos Andinos. Fundación PROINPA, Cochabamba, Bolivia, Cochabamba, Bolivia.

Oke, T.R., 1970. The temperature profile near the ground on calm clear nights. Quarterly Journal of the Royal Meteorological Society 96, 14-23.

Orlander, G., 1993. Shading reduces both visible and invisible frost damage to Norway spruce seedlings in the field. Forestry 66, 27-36.

Peleg, Z., Fahima, T., Abbo, S., Krugman, T., Nevo, E., Yakir, D., Saranga, Y., 2005. Genetic diversity for drought resistance in wild emmer wheat and its ecogeographical associations. Plant Cell and Environment 28, 176-191.

Picó, F.X., Retana, J., de Kroon, H., 2002. An extended flowering and fruiting season has few demographic effects in a Mediterranean perennial herb. Ecology 83, 1991-2004.

Porté, A., Huard, F., Dreyfus, P., 2004. Microclimate beneath pine plantation, semimature pine plantation and mixed broadleaved-pine forest. Agricultural and Forest Meteorology 126, 175-182.

Ruiz, R.A., Bertero, H.D., 2008. Light interception and radiation use efficiency in temperate quinoa (Chenopodium quinoa Willd.) cultivars. European Journal of Agronomy 29, 144-152.

Rundel, P.W., 1994. Tropical alpine climates. In: Rundel, P.W., Smith, A.P., Meinzer, F.C. (Eds.), Tropical Alpine Environments: Plant Form and Function. Cambridge University Press, Cambridge, UK, pp. 21-44.

Scowcroft, P.G., Meinzer, F.C., Goldstein, G., Melcher, P.J., Jeffrey, J., 2000 Moderating night radiative cooling reduces frost damage to Metrosideros polymorpha seedlings used for forest restoration in Hawaii. Restoration Ecology 8, 161-169.

Taschler, D., Neuner, G., 2004. Summer frost resistance and freezing patterns measured in situ in leaves of major alpine plant growth forms in relation to their upper distribution boundary. Plant Cell and Environment 27, 737-746.

Vacher, J.J., 1998. Responses of two main Andean crops, quinoa (Chenopodium quinoa Willd.) and papa amarga (Solanum juzepczukii Buk.) to drought on the Bolivian Altiplano: significance of local adaptation. Agriculture Ecosystems and Environment 68, 99-108.

Varga, B., Svecnjak, Z., Knezevic, M., Grbesa, D., 2004. Performance of prolific and nonprolific maize hybrids under reduced-input and high-input cropping systems. Field Crops Research 90, 203-212.

Viglizzo, E.F., Roberto, Z.E., 1998. On trade-offs in low-input agroecosystems. Agricultural Systems 56, 253-264.

Wang, E., Engel, T., 2002. Simulation of growth, water and nitrogen uptake of a wheat crop using the SPASS model. Environmental Modelling and Software 17, 387-402.

Winkel, T., Méthy, M., Thénot, F., 2002. Radiation-use efficiency, chlorophyll fluorescence and reflectance indices, associated with ontogenic changes in waterlimited Chenopodium quinoa leaves. Photosynthetica 40, 227-232.

Yachi, S., Loreau, M., 1999. Biodiversity and ecosystem productivity in a fluctuating environment: the insurance hypothesis. Proceedings of the National Academy of Sciences 96, 1463-1468. 